Academic Voices

A Multidisciplinary Journal

Volume 6, N0. 1, 2016

ISSN 2091-1106

\title{
CODE-SWITCHING IN CLASSROOM TEACHING
}

\author{
Rajendra Prasad Mahato \\ Department of English Education, TU, Thakur Ram Multiple Campus, Birgunj, Nepal \\ Email:
}

\begin{abstract}
Code-switching refers to the way of communication that bridges two or more linguistic varieties to resister in a single conversation. Especially, in secondary level class-room teachings in English medium schools, ode-switching, for this particular research, has been analyzed and interpreted to conclude that among innumerable reasons deliberately or unknowingly the environment of the classroom mainly feels the echo of code-switching to facilitate understanding for the students. Code-switching, however, is the need the teachers.
\end{abstract}

\section{Key words}

Code-switching; unilingualism; bilingualism; multiling sm; inter-sentential; intrasentential

\section{Introduction}

Code-switching is a term in linguistics referring to alternation between two or more languages or language registers in a single conversation, stretch of discourse, or utterances between people who have more than one language in common. Speakers of more than one language are known for their ability to code switch or mix their language during communication. This phenomenon occurs when bilinguals substitute a word or phrase of one language to a word or a phrase to another language.

Code-switching has been viewed as a strategy to compensate for diminished language proficiency. The concept behind this theory is that bilinguals switch code because they don't know either language completely. This argument is also known as semi-lingualism, which underscores the notion that bilinguals almost speak both languages correctly. However, one concern with this account is that the notion of language proficiency is not clearly defined. It is not clear whether reading and writing language skill should take precedence over spoken language. This reliance on reading and writing is problematic because most bilinguals receive their formal education in onelanguage, whereasa majority of their social interaction takes place in the other language.

Richard (1985) defines it as a change by a speaker (writer) from one language variety to another. Code-switching can take place in a conversation when one speaker uses 
one language and another speaker answers in different languages. A person may start speaking one language and then change to another one in the middle of his speech or sometimes even in the middle of the sentences. Poplack (1980:581) defines code-switching as, "the alternation of two languages within a single discourse, sentence or constituent." Gumperz (1982:59) coined the term conversational code-switching and refers to it as the juxtaposition of passages speech belonging to two grammatical system or subsystems within the exchange. Most frequently the alternation takes the forms of subsequent sentences, as when a speaker uses a second language either to reiterate his massage or to reply someone else's statement. Hudson (1983:56) calls code-switching as, "use of different varieties at different times by single speaker."

Privately run English medium schools of Birgunj claim to use 'English Only' as the medium of instruction in classroom and school premises but the teachers fail to persuade learners towards the absolutely English medium mode. In subjects like Social Studies, some words are directly borrowed from Sanskrit, Nepali or other languages. Trying to translate such words into English will be almost like waste of the time. To teach English grammar and literature also, teachers often switch code. Code-switching in conversation and public discourse has attracted a great deal of attention over the years, most likely because it supports a strong expectation that the communication is made intelligible whatever the language is used. It is not only seen among the learners, teachers but also among other professionals.

Therefore, code-switching has become a global feature. Command of only one language has become a rare phenomenon these days. The knowledge one language has made people paralyzed in this modern age. Bilingualism or multilingualism is the norm for many people throughout the world rather than unilingualism.

\section{Types of code-s witching}

Poplack (1980) has identified the following three types of Code-switching ie. i) Tag Switching, ii) Intersentential Switching, iii) Intrasentential Switching. In Tag Switching, a tag in one language is inserted into an utterance which is otherwise entirely in the other language, for example-'You know, 'I mean' (English tags) 'a 'ho,"hoina '(Nepali tags). It is the most common type of codeswitching.

In Intersentential code-switching, a switch takes place outside the sentence or clause level, where each clause or sentence is shifted into another. It requires greater fluency in both languages than tag switching since major position of the language must confirm to the rules of both languages. An example for Nepali/English discourse is 'Mainle book ta payen but I am yet to get registered.

In Intrasentential code-switching, switching of different types the clause or sen tence occur with in the clause or sentence boundary. For example, 'Exam ko lagi they have prepared.' Intrasentential switches take place within sentence, clause or word boundaries with no apparent change in topic, setting etc.

Most of the linguists describe three kinds of Code-switching i.e situational, metaphorical and conversational. Situational codeswitching occurs when a language is changed according to the situation. The speaker speaks one language in one situation and another in a different one. When a change of topic requires a change in the language, it causes metaphorical code-switching. Nepali speakers use English word while talking about computer. In conversational code-switching, the speaker essentially chooses one code but elements of another code are mixed up in the course of one single utterance.

\section{Reasons for code-s witching}

Code-switching can be more convenient than waiting for one's mind to think of an 
appropriate words or sentences. Likewise, code-switching can help an ethnic minority community retain a sense of cultural identity the sameway that slang is used to give a group of people a sense of identity and belonging, and to differentiate them from a society.

Apart from these reasons, people code switch for a number of reasons:

- Lack of registrar competence

- Mood of the speaker

- Semantic significance

- To show identity in a group

- Pragmatic reasons

\section{Categorization of code-switching}

Studying the nature of the various kinds of code-switching and its categories are described as follows:

\section{i. Gram matical code-switching}

Nepali language in English medium classrooms is not only used for the clarification of the meaning of the items but primarily for the explanation of the grammatical concept, these cases have been put under this category.

\section{a) Code-switching at word level}

Nepali language is used just for teaching word meaning of the English words in questions. These types of cases have been put into this category. The researcher came across with many codes- switching at word level while observing Science and Mathematics classes. For instance; the teacher is never found to use the term bijganit rather he uses al gebra.

\section{b) Code-s witching at phrase level}

A teacher entered in the classroom. All the children were sad because the result of first term was published two days before but most of them were failed in Mathematics. Then teacher began the class with a phrase: 'don't cry over spill milk; try to secure better marks in the second term exam. Students responded his suggestion indifferently. Then he added'Don't cry over spilt milk means 'Biteko kurama chinta garnu hundaina?

\section{c) Code-switching in cla use and sentence Level}

All these cases of code-switching have been put under this category if the sentence and clause structures of the language used in classroom are of $\mathrm{N}$ epali language.

Nepali language is used to clarify the meaning of English sentences and clauses. Almost in all the cases, the use of Nepali language created by the students and teachers fall in this category.

The case 'bujhiyana' (I couldn't understand)', 'maile bujhina (I couldn't understand)', 'sir,' merry' ko meaning ke ho? (Sir, what is the meaning of 'merry'?)' And 'madam, "bring up' ko Nepalima ke hunchha? (Madam, what does 'bring up' mean?)' are of the same nature because they all demand semantic clarification. In the first two cases, thestudents used Nepali to express their own problems and in the last two cases, they used Nepali language to ask questions so that they could understand the meaning of particular English words and phrases. Such cases frequently occurred in the classes in the same form for the same purpose.

'Bujhiyena ho Englishma? (Didn't you understand in English medium?)', 'Nepalima nabhani hundaihundaina' (It is impossible without stating it in Nepali). Teachers make such code-switching when students seem uncomfortable to understand.

'Aru exercise garna sakinchha hoina? (can you solve the remaining exercises?)', 'Timiharu aphu pani garnegarana (you have to try yourself as well).' Generally, the Mathematics and Science teacher asked to the students 
after solving some problems from their sides. Such things are told at the end of a class.

\section{ii. Semantic code-switching}

The sole purpose of the use of Nepali language in English medium classroom is to ensure mutual understanding between the teachers and the students. These cases have been put under this category. The teachers use the Nepali language to get the meaning of the items across to the students and students use Nepali language to ask the questions and to explain their problems. Almost all the cases of code-switching come under this category. So, the case of code-switching under this category has been divided into three categories.

\section{Code-switching for merriment}

Nepali language in English medium classrooms is used not for grammatical explanation and semantic clarification but for creating fun, breaking monotonous, joking. Such cases of code-switching have been put in this category. A teacher said that students wouldn't laugh if the joke is told in English. The essence and feeling does not come to the students when they are told in English.

A teacher introduced a sentence, 'I saw some teddy boys teasing a girl on the way to school.' A student asked the teacher -' what does 'tease' mean sir? "The researcher could clearly guess that the students knew the meaning of the word 'tease', though he asked. The teacher smiled and answered, 'jiskaunu'. All the students laughed for a long time. Here, the students intentionally asked the Nepali meaning of 'tease' to create a sense of fun.

\section{Conclusion}

The factors, which are responsible for creating the situation of code-switching, are outnumbered. The most responsible factor is the background of teachers and students. The existence of multiplicity of languages compels them to speak Nepali knowingly or unknowingly. Similarly, the abstract lexical words dealing with religions, geographical concepts, and the reading comprehension passages that are unrelated to Nepali culture and with difficult words, specialized vocabulary and the literary words demand the use of Nepali. Social Studies are the subjects, which seem to necessitate the maximum use of code-switching, that is, the use of Nepali in English medium classes.

\section{References}

Gumperz, R. ( 1982). Language in Contact. The Hague: M outon, 1982.

Hudson, R. A. (1983). Sociolinguistics. Cambridge: CUP, 1983.

Poplack, W. (1980). An Introduction to Sociolinguistics. Cambridge: CUP, 1980.

Richards, J.; John P. and Heidi W. (1985). Longman Dictionary of Applied Linguistics. Essex: Longman, 1985. 